\title{
Phlebotominae spatial distribution asssociated with a focus of tegumentary leishmaniasis in Las Lomitas, Formosa, Argentina, 2002
}

\author{
O scar Daniel Salomón/ ${ }^{+}$, Pablo Wenceslao O rellano*, Mario Lamfri**, \\ Marcelo Scavuzzo**, Lucía D ri***, María Isabel Farace****, Darío O zuna Q uintana***
}

Centro Nacional de Diagnóstico e Investigación en Endemo-epidemias, Av. Paseo Colón 568, Buenos Aires, Argentina *Ministerio de Salud y Ambiente, Buenos Aires, Argentina **Instituto Mario Gulich, Comisión Nacional de Actividades Espaciales, Córdoba, Argentina ***Ministerio de Desarrollo Humano, Formosa, Argentina ****Instituto Nacional de Enfermedades Infecciosas, Buenos Aires, Argentina

Las Lomitas, Formosa, Argentina, reported 96 cases of tegumentary leishmaniasis during 2002. The urban transmission was suggested although previous outbreaks were related with floods of the Bermejo river (BR) $50 \mathrm{~km}$ from the village. Phlebotomine collections were performed during March 2002 to define the spatial distribution of risk, together with satellite imaginery. The phlebotomine/trap obtained was 1679.5 in the southern BR shore, 1.1 in the periruban-rural environment and 2.3 in the northern Pilcomayo river marshes. Lutzomyia neivai was the prevalent species (91.1\%) among the 2393 phlebotomine captured, and it was only found in the BR traps.

The other species were L. migonei (7.9\%), L. cortelezzii $(0.9 \%)$, and Brumptomyia guimaraesi $(0.1 \%)$. The satellite images analysis indicates that the fishing spots at the BR were significantly overflowed during the transmission peak, consistent with fishermen recollections. This spatial restricted flood might concentrate vectors, reservoirs, and humans in high places. Therefore, both the spatial distribution of vectors and the sensor remoting data suggests that in Las Lomitas area the higher transmission risk it is still related with the gallery forest of the BR, despite of the urban residence of the cases. The surveillance and control implications of these results are discussed

Key words: leishmaniasis - Lutzomyia neivai - remote sensing - ecoepidemiology

Tegumentary leishmaniasis (TL) is endemic in Argentina above $28^{\circ}$ latitude south. This area involves three different ecological regions: the transitional vegetation of the western (Yungas) and eastern (Paranaense) subtropical forests, and the savanna with xeric woods between them (Chaco) (Salomon 2004). Although the disease was known in the country for almost a century, the first recorded outbreak took place in 1984-1987 in the 'Yungas' region, due to L. braziliensis (Sosa Estani et al. 2000, Segura et al. 2000).

Formosa province, in the 'Chaco' region, reported to the National Surveillance System an average of $3.22 \mathrm{TL}$ cases/year from 1955 to 1995, and 9.17 TL cases/year from 1996 to 2000, but the under-reporting was suggested for this period (Basulado et al. 2000). During the last decade most of the cases were diagnosed at the hospital of Las Lomitas, located in the central area of Formosa, with 85 TL cases between 1992 and 2001, 72.9\% of them males, usually related with fishing activities during the periodic floods of the Bermejo river. Further, $99 \%$ of the phlebotomine sand flies captured in Las Lomitas surround-

${ }^{+}$Corresponding author and member of "Carrera del Investigador Científico", Conicet. E-mail:danielsalomon@hotmail.com Received 2 January 2006

Accepted 5 April 2006 ings in December 2001 were collected at the Bermejo river shore, and Lutzomyia neivai was the prevalent species (97.1\%) (Salomon et al. 2002a). Thus, up to 2001 the epidemiological and entomological data indicated for Las Lomitas area the activities at the Bermejo river gallery forest as the main risk factor for TL transmission.

However, from January to July 2002 Las Lomitas Hospital reported $96 \mathrm{TL}$ cases, with residence in Las Lomitas, and so the urban-periurban transmission was suggested, consistent with the urbanization trend of TL transmission in America (Campbell-Lendrum et al. 2001). Therefore, phlebotomine sand flies captures were performed during the peak of case reporting in order to determine the actual spatial distribution of risk, while environmental disturbances were looked for thorough satellite imaginery. The results are presented here and discussed in the frame of spatial transmission and outbreak origin hypotheses, remote sensing tools and appropriate control measures.

\section{MATERIALS AND METHODS}

Studya area - The study was conducted in Las Lomitas city (244ㄹ ' $\left.\mathrm{LS}, 60^{\circ} 35^{\prime} \mathrm{LW}\right)$ and surroundings, department of Patiño, Formosa Province. The department $\left(24,504 \mathrm{~km}^{2}\right)$ is limited to the north by the Pilcomayo river marshes and to the south by the Bermejo-Teuco river. Patiño has 64,830 people, 10,354 of them in Las Lomitas city (Census 2001, National Institute of Statistics and Censuses). The climate is subtropical with a dry season, the landscape is typical of the Chaco ecological region: xeric thorn scrubs, palms, and overexploited woods of 'quebracho' Schinopsis and Aspidosperma. 
Sand fly collections - The capture sites were categorized according to the place and environment in 'Perirubanrural', 'Pilcomayo marshes', and 'Bermejo river' sites (Fig. $1)$. The periurban ones $(n=13)$ were selected taking into account vegetation, water streams, current cases, and supposed places of infection incriminated by the local population. The rural places $(n=5)$ were located up to $12 \mathrm{~km}$ from the city within wooded patches close to cases dwellings or in a deforestation front. The Pilcomayo marshes comprise capture stations from Las Lomitas to the northern border with the Republic of Paraguay $(n=7)$, in two directions: (a) provincial Road 32nd: $60 \mathrm{~km}$ from Las Lomitas, Fortín Soledad village in the peridomestic habitat of cases, and $48 \mathrm{~km}$ in a rural settlement ( 2 sites each); (b) provincial Road 28th: $37 \mathrm{~km}$ and $40 \mathrm{~km}$ in rural peridomestic environments, and $\mathrm{km} 45 \mathrm{~km}$, 'La alcantarilla' in 'Bañado La Estrella' marshes, a fishing and recreational point with patches of palms and Aspidosperma trees. The Bermejo river sites $(\mathrm{n}=2)$ were located $50 \mathrm{~km}$ from Las Lomitas to the southern border with Chaco province at two fishing spots, La Victoria and San Jorge, on the gallery forest of the river shore. Sand flies were captured from 17 to 8 with mini light traps CDC between March 10th and 16th 2002, each site two nights. The temperature range during the trapping nights was $24.3^{\circ} \mathrm{C}-28.7^{\circ} \mathrm{C}$, the relative humidity $71-85 \%$. Captures performed by the same method in two periurban, one rural and La Victoria Bermejo river sites in December 2001, already published (Salomon et al. 2002a), were included in the results for comparative purposes.

Sample processing and data analysis - All captured sand flies were stored dry until identification using the keys of Young and Duncan (1994) and Marcondes (1996). Fisher exact two-tailed test or $\chi^{2}$ test were regarded as significant with associated probabilities $\leq 0.02$ (CI 95\%).

Satellite imaginery - Four satellite images of the study area (Path/Row 228/77) from two consecutive years were used. Two images were from dates with low Bermejo river flow (09/28/2000 and 15/09/2001), and the others from dates immediately after the annual flood (05/18/2001 and 05/21/2002). The former two were Landsat 5 TM and the latter Landsat 7 ETM, all provided by Conae. Although the maximal and minimal flow of the Bermejo river recorded for both years were in March and October respectively, the images were the closest available to these dates. The images were georreferenced using satellite ephemeris and the nearest-neighbor method. The Band 5 (reflected midinfrared) was used in order to discriminate areas covered by the river (values of digital number-DN- between 0 and 22) and the surrounding land uncovered of vegetation (visual identification). The uncovered shores, data from May image minus that of September of the previous year, were regarded as a quantitative indicator of the flood area during March.

\section{RESULTS}

Phlebotomine captures in March 2002 produced 2393 sand flies in 10 out of the 27 sites sampled. L. neivai ( $L$. intermedia complex) was the prevalent species $(91.1 \%)$, L. migonei (7.9\%), L. cortelezzii ( $0.9 \%)$, and B. guimaraesi $(0.1 \%)$ were also found (Table). The abundance were significantly higher in the gallery forest of the Bermejo river than the Pilcomayo marshes basin or the periurban-rural sites: $1679.5,2.3$ and 1.1 phlebotomine/trap respectively. The species composition also differs among the three environments.

L. neivai was only collected in the Bermejo river associated vegetation, which it is also the unique environment with gravid females, L. migonei (15.7\% of females), L. neivai (7.3\%). Although no permanent human population is living there both sites on the river shore were usually visited for fishing, and the one with higher proportion of $L$. neivai was close to a water pumping station out of service.

Periurban-rural captures were consistently lower than Bermejo captures, sand flies were collected in 3 out of 13 periurban places and in 1 out of 5 rural sites. L. migonei and $L$. cortelezzii were represented by scarce individuals, but both species were present in almost all traps in the city vegetated surroundings that collected phlebotomine. The Pilcomayo marshes traps only produces L.migonei, the higher capture (11 individuals) in the peridomestic environment of a case located in Fortin Soledad village.

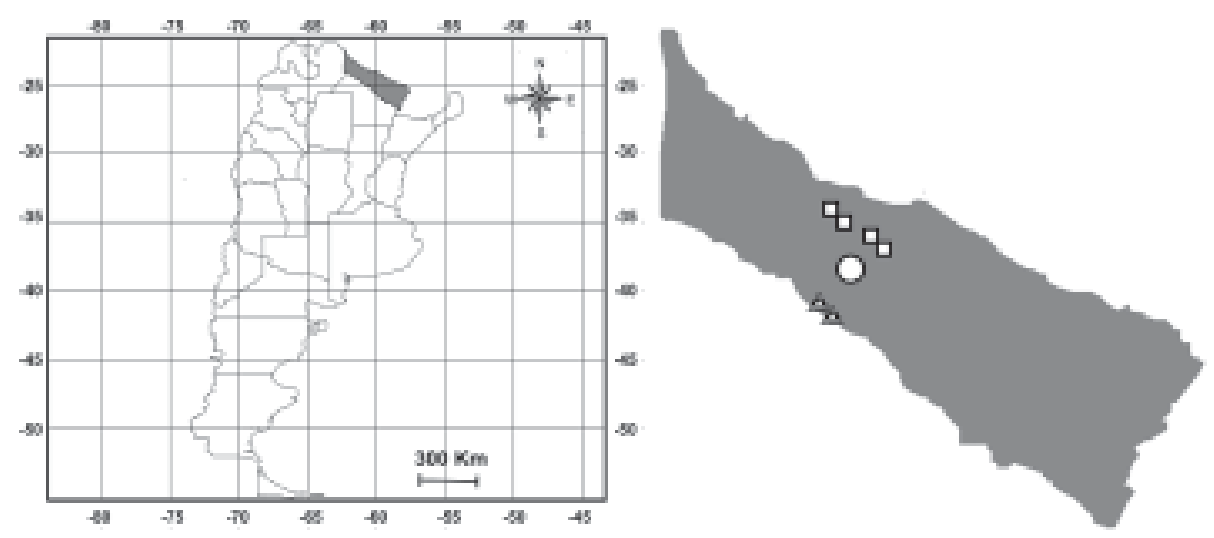

Fig. 1: phlebotomine capture stations, Formosa province, Argentina, March 2002. Las Lomitas periurban and rural sites (circle), Pilcomayo river marsh sites (squares), and Bermejo river sites (triangles). 
Captures performed in December 2001 in the same area by mini light traps collected 966 individuals, L. neivai 98\%, L.migonei $1.7 \%$, and L.cortelezzii $0.3 \%$; $99.7 \%$ of the overall capture was made in the Bermejo river shores, the remaining $4 L$. neivai were found in peripheral sites of Las Lomitas city (Table). The captures at the Bermejo river site from December 2001 and March 2002 did not differ significantly either in abundance, species relative abundance or sex proportion of $L$. neivai and L. migonei. B. guimaraesi first report in Formosa province was only found in March 2002 Bermejo captures. On the other hand, periurban $L$. neivai was only collected in December 2001, while periurban $L$. migone $i$ and $L$. cortelezzii were already reported in Las Lomitas previous captures with Shannon modified trap (Salomon et al. 2002a).

The satellite imaginery of the Bermejo river $50 \mathrm{~km}$ from Las Lomitas (Fig. 2) shows a larger area of uncovered land on the shore at the fishing spot in the May 2001September 2002 images, than in May 2000-September 2001 ones. Therefore, these areas at this particular bend of the river were computed for each series (May minus September) and they were significantly different: 2000/2001-124.2 $\mathrm{km}^{2}$, and 2001/2002-710.1 $\mathrm{km}^{2}$.

\section{DISCUSSION}

Phlebotomine captures performed close to the BermejoTeuco river in Las Lomitas area during an 'urban' outbreak collected $L$. neivai as the prevalent species (> 90\%) with gravid females, followed by $L$. migonei and less $L$. cortelezzii. Thus, sand fly abundance and species composition within the gallery forest of the Bermejo river in the 'Chaco' region are the same as those found in the western hyperendemic area of TL transmission, in the foothills of the "Yungas" subtropical forest on the same Bermejo river basin (Salomon et al. 2004), and different from those found in the eastern subtropical forest (Salomon et al. 2002b). On the other hand, the perirubanrural and Pilcomayo marshes collections, with scarce in-

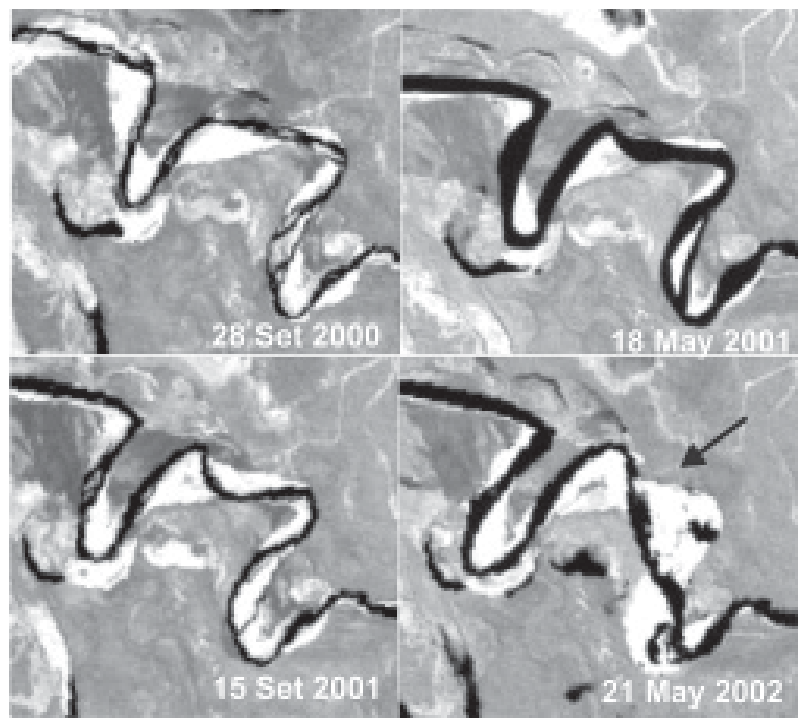

Fig. 2: Bermejo river shore, Las Lomitas area of influence (Provincial Road 28th south). Landsat 5 TM (09/28/2000, 15/09/2001) and Landsat 7 ETM (05/18/2001 and 05/21/2002). The arrow indicates the fishing site, in black the river course, in white the surrounding land uncovered of vegetation regarded as an indicator of the extent of the previous flood.

dividuals of $L$. cortelezzii and $L$. migonei resemble the captures reported up to 1950 in 'Chaco' landscapes of Formosa province where TL transmission was sporadic (Bejarano \& Duret 1950). Historical collections also recorded for the province L. shannoni in San Hilario (Castro 1959), and L. intermedia s.l. in the Bermejo- Paraguay rivers confluence (Del Ponte 1960).

$L$. intermedia complex species (L. intermedia or $L$. neivai) and $L$. migonei have been incriminated as suspected vectors of Leishmania braziliensis, the former in domestic foci of Brazil, Paraguay, and Argentina (Rangel

TABLE

Phlebotomine captured with mini light trap (two nights) by species, sex (females/males), and site (only sites with sand flies) at different environments in Las Lomitas area, Formosa province, Argentina, March 2002. Captures performed during December 2001, already published (Salomón et al. 2002a) were also included

\begin{tabular}{|c|c|c|c|c|c|c|c|}
\hline Station & Date & Coordenates & $L n$ & $L m$ & $L c$ & $B g$ & Total \\
\hline \multirow[t]{3}{*}{ Bermejo river } & $12 / 01$ & $25^{\circ} 01$ '14"LS, 6050’27"LW & $689 / 254$ & $9 / 7$ & $3 / 0$ & 0 & 962 \\
\hline & $03 / 02$ & $25^{\circ} 01^{\prime} 14^{\prime \prime L S}, 60^{\circ} 50^{\prime} 27^{\prime \prime L W}$ & $717 / 268$ & $11 / 8$ & $3 / 0$ & 0 & 1007 \\
\hline & $03 / 02$ & $25^{\circ} 01^{\prime} 12^{\prime \prime L S}, 60^{\circ} 52^{\prime} 62^{\prime \prime} \mathrm{LW}$ & $581 / 615$ & $83 / 50$ & $9 / 6$ & $1 / 0$ & 1345 \\
\hline \multirow[t]{5}{*}{ Periurban- rural } & $12 / 01$ & $24^{\circ} 41^{\prime} 15^{\prime \prime L S}, 60^{\circ} 35^{\prime} 22^{\prime \prime L W}$ & $2 / 2$ & 0 & 0 & 0 & 4 \\
\hline & $03 / 02$ & $24^{\circ} 41^{\prime} 15^{\prime \prime L S}, 60^{\circ} 35^{\prime} 22^{\prime \prime L W}$ & 0 & $3 / 2$ & $0 / 3$ & 0 & 3 \\
\hline & $03 / 02$ & $24^{\circ} 41^{\prime} 23^{\prime \prime L S}, 60^{\circ} 35^{\prime} 9^{\prime \prime L W}$ & 0 & $6 / 2$ & $1 / 0$ & 0 & 9 \\
\hline & $03 / 02$ & $24^{\circ} 41^{\prime} 67^{\prime \prime L S}, 60^{\circ} 37^{\prime} 30^{\prime \prime L W}$ & 0 & $2 / 2$ & $1 / 2$ & 0 & 7 \\
\hline & $03 / 02$ & $24^{\circ} 43^{\prime} 14^{\prime \prime L S}, 60^{\circ} 35^{\prime} 07^{\prime \prime L W}$ & 0 & $1 / 0$ & 0 & 0 & 1 \\
\hline \multirow[t]{4}{*}{ Pilcomayo basin } & $03 / 02$ & $24^{\circ} 26^{\prime} 62^{\prime \prime L S}, 60^{\circ} 22^{\prime} 54^{\prime \prime L W}$ & 0 & $1 / 2$ & 0 & 0 & 3 \\
\hline & $03 / 02$ & $24^{\circ} 24^{\prime} 55^{\prime \prime L S}, 60^{\circ} 20^{\prime} 05^{\prime \prime} \mathrm{LW}$ & 0 & $1 / 0$ & 0 & 0 & 1 \\
\hline & $03 / 02$ & $24^{\circ} 14^{\prime} 19^{\prime \prime L S}, 60^{\circ} 37^{\prime} 69^{\prime \prime} \mathrm{LW}$ & 0 & $1 / 0$ & 0 & 0 & 1 \\
\hline & $03 / 02$ & $24^{\circ} 08^{\prime} 97^{\prime \prime L S}, 60^{\circ} 41^{\prime} 40^{\prime \prime} \mathrm{LW}$ & 0 & $9 / 2$ & 0 & 0 & 11 \\
\hline Total & & & 3128 & 202 & 28 & 1 & 3359 \\
\hline
\end{tabular}

Ln: Lutzomyia neivai; Lm: L. migonei; Lc: L.cortelezzii; Bg: Brumptomyia guimaraesi. 
et al. 1990, Salomon et al. 2004), the second one in peridomestic habitats that usually involves dogs and horses (Aguiar et al. 1987, Azevedo et al. 1990). Therefore, the spatial distribution of sand flies reported here suggest a relative risk much higher in the Bermejo river area than that in the urban or Pilcomayo area. Further, in a simultaneous epidemiological study (to be published elsewhere) the visit to the river risk sites differs significantly between cases and leishmanine negative controls (OR 0.59 $<2.29<8.99$ ).

The TL cases recall the starting skin lesion between October 2001 and April 2002 with the mode and the median in March 2002. The seasonal distribution of the cases diagnosed in Las Lomitas hospital from 1992 to 2001, based on the probable date of infection was significantly associated with the average river flow (May-June) of the same year and the cumulative rainfall (January- May) of the previous year (Salomon et al. 2002a). However, neither the rainfall nor the Bermejo river flow showed any difference related to the 2002 outbreak. The 2001 JanuaryMay cumulative rainfall was $598.9 \mathrm{~mm}$ and it did not differ significantly from the 1990-2000 average $418.2( \pm 180.0)$ $\mathrm{mm}$ or the 2000 precipitation $510.1 \mathrm{~mm}$ (National Service of Meteorology, Argentine Air Force). Bermejo river, El Colorado hydrologic station on the other hand, the closest to the study area $\left(26^{\circ} 20^{\prime} 00^{\prime \prime} \mathrm{LS}, 59^{\circ} 21^{\prime} 49^{\prime \prime} \mathrm{LW}, 78 \mathrm{masl}\right)$, recorded flow over $1000 \mathrm{~m}^{3} / \mathrm{s}$ only from February to March, but these records did not differ significantly between the year $2000\left(1394 \pm 282,8 \mathrm{~m}^{3} / \mathrm{s}\right), 2001\left(1168 \pm 275,4 \mathrm{~m}^{3} / \mathrm{s}\right)$ and $2002\left(1238 \pm 157,2 \mathrm{~m}^{3} / \mathrm{s}\right)$ (Sistema Nacional de Información Hídrica, National Hydrologic Network, EVARSA). Nevertheless, the satellite imaginery showed a focal overflow just at the fishing spots during the TL transmission period (Salomon et al. 2004). Unfortunately the images from March were unavailable due to cloudiness or technical problems, so the uncovered post-flood land in May next to the shores were used as an indicator of the extent of the previous flood, consistent with the fisherman recollections. This spatial restricted flood might concentrate vectors, potential reservoirs and humans in high places increasing both the parasite circulation, and the humanvector effective contact.

In conclusion, in Las Lomitas area the higher TL transmission risk it is still related with activities within the gallery forest of the Bermejo river, despite of the urban residence of the cases. However, the cases in Fortin Soledad (Pilcomayo river) and the presence of L. neivai in Las Lomitas city suggested a peridomestic cycle with sporadic cases or lower magnitude overlapped to the sylvatic one. In this scenario an spatial intervention against the vector in the urban area will have none or little impact on the TL incidence, even during the transmission peak, further when it was required during the peak of case diagnoses after the end of the vector season. Besides, from the sand fly ecology point of view the forest associated with the Bermejo river is a 'Yungas' subtropical forest corridor in the 'Chaco' xeric region, while the captures performed in Las Lomitas and Pilcomayo river better represents the 'Chaco' fauna.

Finally, the TL incidence in the area up to 2001 was fairly associated with climatic and hydrological regular records, but the cases above average reported from Las Lomitas Hospital during the first half of 2002 are related with an overflow at a fishing point tracked only by satellite imaginery. Thus, remote sensing would be useful for microfocal surveillance of TL transmission, in space to conceive local adapted recommendations, and in time to active early warning systems. The Bermejo river basin could be surveilled at fishing points during the periodic overflows and each site categorized as sound, to be visited with personal protection, or to be avoided or banned. In the last ones areas the primary health care agents will be warned to perform active search of new TL cases. However, should be noted that the 2001 economic crisis turned recreational fishing and hunting to subsistence activities for an increasing number of people, and so the fulfillment of the recommendations will be dubious. Further, there are projects of deforestation and irrigation from the Bermejo river toward urban areas that will change the landscape and the sand fly abundance where L. neivai is already present. Thus, together with the surveillance and monitoring of the environment with remote sensing data, the impact on TL transmission should be included in the Environment Impact Assessment demanded to project developers in the endemic TL areas, in order to avoid an actual peridomestic cycle and urban-periurban outbreaks in the region.

\section{ACKNOWLEDGMENTS}

To Dr Marta Donnet, Mónica Galarza (Las Lomitas Hospital); to Major Ing. José Figueroa, Secretary Antonio Ledesma (Las Lomitas Municipality); to Comandante Principal Arnaldo Vazquez (Gendarmería Escuadrón 18) and to Dr Mario Zaidenberg and the agents of the National Coordination of Vector Control for assistance during fieldwork.

\section{REFERENCES}

Aguiar GM, Vilela ML, Lima RB 1987. Ecology of the sandflies of Itagauí, an area of cutaneous leishmaniasis in the state of Rio de Janeiro, food preferences (Diptera, Psychodidae, Phlebotominae). Mem Inst Oswaldo Cruz 81: 477-479.

Azevedo ACR, Rangel EF, Queiroz RG 1990. Lutzomyia migonei (França, 1920) naturally infected with perypylarian flagellates in Baturité, a focus of cutaneous leishmaniasis in Ceará State, Brazil. Mem Inst Oswaldo Cruz 85: 479.

Basualdo M, Muracciole E, Rodriguez C 2000. Leishmaniosis y la información. Medicina (Buenos Aires) 60 (Supl. III): 65.

Bejarano JFR, Duret JP 1950. Contribución al conocimiento de los flebótomos Argentinos (Diptera, Psychodidae). Rev Sanidad Militar Argentina 49: 327-336.

Campbell-Lendrum D, Dujardin JP, Martinez E, Feliciangeli MD, Enrique Perez J, Passerat de Silans LNM, Desjeux P 2001. Domestic and peridomestic transmission of American cutaneous leishmaniasis: changing epidemiological patterns present new control opportunities. Mem Ins Oswaldo Cruz 96: 159-162.

Castro M 1959. Diptera: Psychodidae-Flebotominae. In JRF Bejarano, E del Ponte, RN Orfila (eds), Primeras Jornadas Entoepidemiológicas Argentinas, La Prensa Médica, Buenos Aires, p. 545-546.

Del Ponte E 1960. Distribución y conocimiento actual de la 
leishmaniosis en la Argentina. Primer Congreso Sudamericano de Zoología, T1, p. 211-241.

Marcondes CB 1996. Redescription of Lutzomyia (Nyssomyia) intermedia (Lutz \& Neiva, 1912), and resurrection of $L$. neivai (Pinto, 1926) (Diptera, Psychodidae, Phlebotominae). Mem Inst Oswaldo Cruz 97: 457-462.

Rangel, EF, Azevedo ACR, Andrade CA, Souza NA Wermelinger ED 1990. Studies on sandfly fauna (Diptera: Psychodidae) in a focus of cutaneous leishmaniasis in Mesquita, Rio de Janeiro State, Brazil. Mem Inst Oswaldo Cruz 85: 39-45.

Salomón OD 2002. Leishmaniosis: vectores y brotes epidémicos en Argentina. In OD Salomón, Actualizaciones en Artropodología Sanitaria Argentina, Fundación Mundo Sano, Buenos Aires, p. 185-196.

Salomón OD 2004. Leishmaniasis. In R Cacchione, R Durlach, O Larghi (eds), Temas de Zoonosis II, Asociación Argentina de Zoonosis, Buenos Aires, p. 281-289.

Salomón OD, Sosa Estani S, Dri L, Donnet M, Galarza R, Recalde H, Tijera A 2002a. Leishmaniosis tegumentaria en Las Lomitas, provincia de Formosa, Argentina, 1992-2001. Medicina (Buenos Aires) 62: 562-568.

Salomón OD, Rossi GC, Spinelli GR. 2002b. Ecological as- pects of phelobotomine (Diptera, Psychodidae) in an endemic area of tegumentary leishmaniasis in the Northeastern Argentina, 1993-1998. Mem Inst Oswaldo Cruz 97: 163168.

Salomón OD, Wilson ML, Munstermann LE, Travi BL 2004. Spatial and temporal patterns of phlebotominae sand flies (Diptera: Psychodidae) in a cutaneous leishmaniaisis focus in Northern Argentina. J Med Entomol 41: 33-39.

Segura EL, Juan N, Piquin AL, Cuba Cuba CA, Abramo Orrego L, McMahon-Pratt D, Montamat EE, Momen H, Grimaldi Jr G 2000. Molecular and biologic characterization of Leishmania parasites implicated in an epidemic outbreak in northwestern Argentina. Parasitol Res 86: 504-508.

Sosa Estani S, Segura EL, Salomón 0D, Gómez A, Peralta M, Coutada V 2000. Tegumentary leishmaniasis in Northern Argentina: distribution of infection and disease, in three municipalities of Salta, 1990-1992. Rev Soc Bras Med Trop 33: 573-582.

Young DG, MA Duncan 1994. Guide to the identification and geographic distribution of Lutzomyia sand flies in Mexico, the West Indies, Central and South America (Diptera: Psychodidae). Mem Am Entomol Inst 54: 1-881. 